\title{
Survival and risk factors for progression after resection of the dominant tumor in multifocal, lepidic-type pulmonary adenocarcinoma
}

\author{
Rebecca W. Gao, MS, ${ }^{\mathrm{d}}$ Mark F. Berry, MD, MSE, MHS, ${ }^{a}$ Christian A. Kunder, MD, PhD, ${ }^{b}$ \\ Amanda A. Khuong, BS, ${ }^{a}$ Heather Wakelee, MD, ${ }^{c}$ Joel W. Neal, MD, PhD, ${ }^{c}$ \\ Leah M. Backhus, MD, MPH, ${ }^{\mathrm{a}, \mathrm{e}}$ and Joseph B. Shrager, MD ${ }^{\mathrm{a}, \mathrm{e}}$
}

\begin{abstract}
Background: It remains unclear whether a dominant lung adenocarcinoma that presents with multifocal ground glass opacities (GGOs) should be treated by local therapy. We sought to address survival in this setting and to identify risk factors for progression of unresected GGOs.

Methods: Retrospective review of 70 patients who underwent resection of a pN0, lepidic adenocarcinoma, who harbored at least 1 additional GGO. Features associated with GGO progression were determined using logistic regression and survival was evaluated using the Kaplan-Meier method.
\end{abstract}

Results: Subjects harbored 1 to 7 GGOs beyond their dominant tumor (DT). Mean follow-up was $4.1 \pm 2.8$ years. At least 1 GGO progressed after DT resection in 21 patients $(30 \%)$. In 11 patients $(15.7 \%)$, this progression prompted resection $(\mathrm{n}=5)$ or stereotactic radiotherapy $(\mathrm{n}=6)$ at mean $2.8 \pm 2.3$ years. Several measures of the overall tumor burden were associated with GGO progression (all $P$ values $<.03$ ) and with progression prompting intervention (all $P$ values $<.01$ ). In logistic regression, greater DT size (odds ratio, $1.07 ; 95 \%$ confidence interval, 1.01-1.14) and an initial GGO $>1 \mathrm{~cm}$ (odds ratio, $4.98 ; 95 \%$ confidence interval, 1.15-21.28) were the only factors independently associated with GGO progression. Survival was not negatively influenced by GGO progression ( $100 \%$ with vs $80.7 \%$ without; $P=.1$ ) or by progression-prompting intervention $(P=.4)$.

Conclusions: At 4.1-year mean follow-up, $15.7 \%$ of patients with unresected GGOs after resection of a pNO DT underwent subsequent intervention for a progressing GGO. Some features correlated with GGO growth, but neither growth, nor need for an intervention, negatively influenced survival. Thus, even those at highest risk for GGO progression should not be denied resection of a DT. (J Thorac Cardiovasc Surg 2017;154:2092-9)

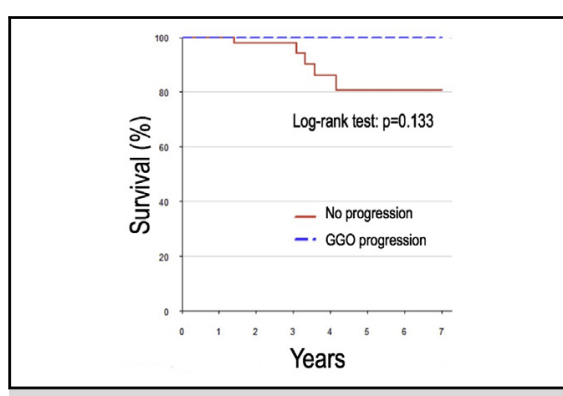

Survival in patients with and without GG0 progression were not significantly different.

\section{Central Message}

Patients with unresected ground glass opacities (GGOs) after resection of a pNO dominant tumor (DT) should not be denied DT resection, because neither GGO growth nor intervention for a progressing GGO decreases survival.

\section{Perspective}

This is the largest series of patients undergoing resection of lepidic-type adenocarcinomas who bear multifocal ground glass opacities (GGOs). A still incompletely resolved question is whether these patients should be considered resectable. We establish that they should be treated aggressively with local therapy for dominant, invasive tumors, with expectation for long survival.

See Editorial Commentary page 2100.
Lepidic-type adenocarcinomas (in situ, minimally invasive, and lepidic-predominant adenocarcinomas), are subtypes of lung adenocarcinoma that have recently been defined. ${ }^{1}$ These tumors present radiographically as partially or

From the a Division of Thoracic Surgery, Department of Cardiothoracic Surgery, ${ }^{\mathrm{b}}$ Department of Pathology, and ${ }^{\mathrm{c} D}$ Division of Oncology, Department of Medicine, ${ }^{\mathrm{d}}$ Stanford University School of Medicine, Stanford, Calif; and ${ }^{\mathrm{e}}$ Veterans Affairs Palo Alto Health Care System, Palo Alto, Calif.

R.W.G. was supported by a scholarship from The American Association for Thoracic Surgery.

More than 7 authors participated because the collection and analysis of the data extended over several years, requiring rotating involvement of individuals who at some point moved on, as well as because of the multidisciplinary nature of the study, including oncologists and pathologists. entirely ground glass opacity (GGO), ${ }^{2-7}$ and they display a number of distinctive clinical features, including a high prevalence of epidermal growth factor receptor (EGFR) mutations, a tendency to occur in Asians and

\footnotetext{
Read at the 96th Annual Meeting of The American Association for Thoracic Surgery, Baltimore, Maryland, May 14-18, 2016.

Received for publication Jan 11, 2017; revisions received June 28, 2017; accepted for publication July 16, 2017; available ahead of print Aug 29, 2017.

Address for reprints: Joseph B. Shrager, MD, Stanford University Hospital, 300 Pasteur Dr, MC 5407, Falk Bldg, Stanford, CA 94305-5407 (E-mail: shrager@ stanford.edu).

0022-5223/\$0.00

Published by Elsevier Inc. on behalf of The American Association for Thoracic Surgery

http://dx.doi.org/10.1016/j.jtcvs.2017.07.034
} 


\section{Abbreviations and Acronyms \\ CT = computed tomography \\ DT = dominant tumor \\ EGFR = epidermal growth factor receptor \\ GGO = ground glass opacity \\ PET = positron emission tomography \\ SBRT = stereotactic radiotherapy \\ SUVmax $=$ standardized uptake value}

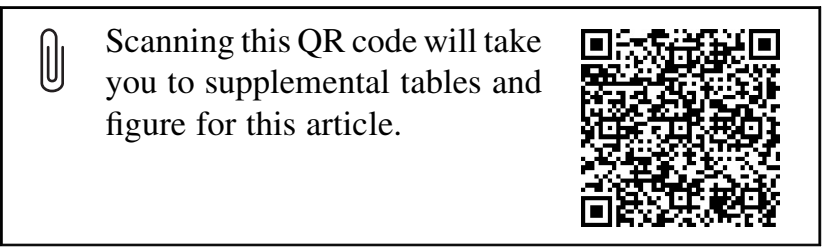

nonsmokers, ${ }^{1,8-10}$ and a lower propensity for lymph node and distant metastasis in comparison to solid adenocarcinomas of the same diameter. ${ }^{1,11-19}$

Another important feature of lepidic-type tumors is their remarkable tendency (suggested to be around $20 \%$ by some studies) to present with multifocal parenchymal nodulesthe focus of this study. ${ }^{20}$ Critical questions for patients in whom these tumors present multifocally is whether they should be considered metastatic (or at least, to have a poor prognosis) and thus undergo systemic, rather than (or in addition to) local therapies-tempting options because these tumors are often sensitive to tyrosine kinase inhibitors. With traditional, solid non-small cell lung cancers, criteria have been proposed over the years to help determine the likelihood of multifocal lesions to represent separate primary tumors versus metastases. ${ }^{21}$ Many patients with solid tumors are, on the basis of these criteria, appropriately treated with systemic rather than local therapies.

We and others have previously reported smaller cohorts of patients with multifocal, lepidic-type adenocarcinomas (typically bearing one dominant, invasive lesion). ${ }^{22-28}$ These studies suggested preliminarily that these patients do not behave as though they have stage IV or IIIA disease. ${ }^{20,29,30}$ That is, they do not appear to behave as the majority of patients with solid, multifocal tumors behave. These previous publications have each been limited by 1 or more of the following problems: small sample size, short mean follow-up time (particularly given the known slow growth rate of GGOs), and/or a focus exclusively upon Asian patients (thus limiting the generalizability of the findings to white patients).

We therefore studied a larger group of mixed white and Asian patients, with extended longitudinal follow-up, to address the remaining questions about patients with multifocal, lepidic-type adenocarcinoma of the lung, including determining the risk factors for progression of untreated GGOs in this setting. We sought to determine whether there are preoperative identifiers associated with progression/poor prognosis that may render a subset of these patients inappropriate for surgical (or other local) therapy.

\section{PATIENTS AND METHODS \\ Study Design}

We performed a retrospective review of 70 patients undergoing operation at Stanford University Hospital between December 2001 and January 2015 for a pN0, lepidic-containing adenocarcinoma as the resected dominant tumor (DT), who harbored at least 1 additional pure or predominately GGO nodule. A DT was defined as a tumor that was substantially larger than other ground glass nodules and contained radiographic features (eg, solid areas on computed tomography [CT], elevated maximum standardized uptake value [SUVmax] on positron emission tomography [PET]/ $\mathrm{CT}$, or size $>1.5 \mathrm{~cm}$ ) suggesting that resection was indicated. The Stanford University Institutional Review Board granted the study exemption from the need for informed consent.

To identify our study group, we first identified patients who underwent resection of lung adenocarcinomas described pathologically as bronchioloalveolar, bronchoalveolar carcinoma, adenocarcinoma in situ of the lung, minimally invasive adenocarcinoma of lung, or lepidic. Slides were reviewed by a pathologist to confirm the presence of a lepidic component. Preoperative CT scans were reviewed to identify the subgroup of these patients who preoperatively bore at least 1 separate, synchronous GGO lesion. We excluded patients with pathologic nodal disease, DTs $>5 \mathrm{~cm}$ in diameter, positive margins of resection, and those with $>10$ GGOs.

Routine follow-up was CT and office visit every 6 months for 2.5 years, then yearly to 5.5 years. Nondominant GGOs being followed were generally treated, by either surgical resection or stereotactic radiotherapy (SBRT), when they reached $>1 \mathrm{~cm}$ in size with any solid component, or $>1.5 \mathrm{~cm}$ in size if entirely ground glass. Patients who had not been seen within 6 months of data analysis (due to being beyond 2.5 years after surgery) were contacted for telephone follow-up.

Locoregional and distant recurrence, survival status, and GGO-specific progression were recorded. Patient and tumor characteristics were analyzed to identify factors associated with overall and progression-free survival, GGO progression, and GGO progression requiring a therapeutic intervention. GGO progression was defined as growth of a GGO, development of a new solid component in a pure GGO, enlargement of a solid component in part-solid GGO with stable total diameter, or development of a new GGO. Locoregional recurrence was defined as recurrence in a staple line adjacent to prior resection of a DT or in the hilum or mediastinum ipsilateral to previously resected DT. Distant recurrence was defined as development of a metastasis outside of the lungs or the growth of a solid nodule(s) $>5 \mathrm{~mm}$ in size in ipsilateral or contralateral lungs. Disease-free survival was defined as patients without extrapulmonary metastases, locoregional or distant recurrence, or GGO progression requiring an intervention. Overall survival was calculated from the date of surgery until either death from any cause or date of last follow-up, with a minimum of 1.5 years of study inclusion. Variables considered included ethnicity, stage and size of the DT, genetic mutations, smoking status, and number and size of the nondominant GGOs.

\section{Statistical Methodology}

Univariate analysis was used to compare characteristics between patients who did and did not have GGO progression and between patients who did or did not undergo intervention for GGO progression. Logistic regression analyses were conducted to determine significant prognostic factors, with separate models developed with both GGO progression and GGO progression requiring intervention as outcomes. The number of 
TABLE 1. Characteristics and surgical procedures of 70 patients with multifocal lepidic-type adenocarcinomas of the lung

\begin{tabular}{|c|c|}
\hline Patient characteristic & Result $(\mathbf{N}=\mathbf{7 0})$ \\
\hline \multirow[t]{2}{*}{ Age (y) } & $70.0 \pm 6.4$ \\
\hline & $71[66-77]$ \\
\hline \multicolumn{2}{|l|}{ Sex } \\
\hline Male & $19(27)$ \\
\hline Female & $51(73)$ \\
\hline \multicolumn{2}{|l|}{ Ethnicity } \\
\hline Asian & $25(36)$ \\
\hline Hispanic & $2(3)$ \\
\hline African American & $3(4)$ \\
\hline Non-Hispanic white & $40(57)$ \\
\hline \multicolumn{2}{|l|}{ Smoking history } \\
\hline Never & $29(41)$ \\
\hline Minimal $(\leq 5$ pack-y) & $6(9)$ \\
\hline More than minimal & $35(50)$ \\
\hline \multicolumn{2}{|l|}{ Previous cancer history } \\
\hline Yes & $23(33)$ \\
\hline No & $47(67)$ \\
\hline \multicolumn{2}{|l|}{ Surgical procedures } \\
\hline \multicolumn{2}{|l|}{ Operation } \\
\hline Open Thoracotomy & $20(29)$ \\
\hline Video-assisted thoracoscopy & $50(71)$ \\
\hline \multicolumn{2}{|l|}{ Resection type } \\
\hline Lobectomy & $41(59)$ \\
\hline Segmentectomy & $5(7)$ \\
\hline Wedge & $15(21)$ \\
\hline Combination & $9(13)$ \\
\hline
\end{tabular}

potential associated factors included in the models were intentionally limited due to consideration of the number of events, and we selected those that were statistically significant in univariate analysis and also were believed to be most clinically relevant. Overall survival was calculated from the date of surgery and estimated using Kaplan-Meier analysis (separately for GGO progression and GGO progression requiring intervention).

Continuous data are presented as mean and interquartile ratio. Baseline characteristics between groups were compared with the Wilcoxon ranksum test for continuous variables and Pearson $\chi^{2}$ test for discrete variables. Categorical variables are presented as frequency and percentages and were compared using $\chi^{2}$ or Fisher exact test. Multivariate logistic regression results are presented as odds ratios and $95 \%$ confidence intervals. Differences between curves were evaluated using log-rank tests. Statistical analyses were performed using Excel 14.1 (Microsoft Corp, Redmond, Wash), Stata 13 software (StataCorp, College Station, Tex), the SAS 9.2 statistical package (SAS Institute, Cary, NC), and R 2.15.1 (R Foundation for Statistical Computing, Vienna, Austria)

\section{RESULTS}

\section{Patient and Surgery Characteristics}

Patient and surgical characteristics are summarized in Table 1. There were 70 patients. Follow-up was complete in $100 \%$ of patients. Mean follow-up time was $4.1 \pm 2.8$ years (range, 1.1-13.6 years; median, 3.04 years).

The population was predominantly non-Hispanic white $(57 \%)$ and Asian (36\%). Fifty percent of patients had an over 5 pack-year cigarette smoking history and $41 \%$ were lifelong nonsmokers.

Twenty patients (29\%) underwent a thoracotomy and 50 $(71 \%)$ underwent video-assisted thoracoscopic resections. The operations typically removed the DT and any accessible ipsilateral GGOs. For the DT, lobectomy was performed in $59 \%$ of the patients and anatomic segmentectomy in $21 \%$. Seven percent underwent wedge resection(s) alone and $13 \%$ underwent a combination anatomic resection for the DT and wedge for an accessible GGO.

Sixty-two patients $(89 \%)$ received PET/CT scans before DT resection. The average SUVmax of the DT was 3.3 with a range of nonavid to 18.0. Other GGOs were hypermetabolic in only 3 patients ( 3 out of $62[5 \%]$ ) who received PET/CT scans with an average SUVmax of 1.2. Four patients (out of $62[6 \%]$ ) had at least 1 hypermetabolic lymph node, with an average SUVmax of 3.4. Six patients (9\%) underwent mediastinoscopy and 2 patients $(3 \%)$ underwent endobronchial ultrasound with needle aspirations before DT resection.

\section{Characteristics of the DT and the GGOs}

Characteristics of the DT and the GGOs are summarized in Table 2. Radiographically, the DTs were mean $20.0 \mathrm{~mm}$ diameter (range, 4-49 mm) and 52.6\% solid (range, 10\%$90 \%)$. Histologically, the DTs were mostly well $(48 \%)$ or moderately $(48 \%)$ differentiated. Sixty-three percent of DTs (ignoring the GGOs in staging) were pathologic stage IA, $26 \%$ were stage IB, and $4 \%$ were stage IIA. $7 \%$ were stage 0 (pure in situ). Of the 43 DTs that underwent mutation analysis for EGFR mutations, 24 (24 out of 43 [56\%]) were positive. Two (out of 39 [5\%]) were ALK positive, and 6 (out of $42[14 \%]$ ) were KRAS positive.

Of 9 patients who had an additional GGO removed along with the DT at the original surgery, 7 GGOs were determined on pathology to be well-differentiated adenocarcinomas with bronchoalveolar carcinoma features (this was before institution of the modern terminology for these lesions), 1 GGO was a moderately differentiated invasive adenocarcinoma of mixed subtype, and 1 GGO was a small abscess.

The patients had an average of 1.8 (range, 1-7) nondominant GGOs at presentation with a mean size of $6.1 \mathrm{~mm}$ (range, 2-23 mm). Forty-eight GGOs $(39 \%)$ were ipsilateral to the DT and $76(61 \%)$ were contralateral.

\section{Postoperative Outcomes}

Table 3 lists the results from postoperative surveillance. Twenty-one $(30 \%)$ patients had 1 or more modes of progression of unresected GGOs. In 19 patients $(27 \%)$, there was growth, with an average increase of $5.0 \mathrm{~mm}$ (range, 2-25 mm). Nineteen patients $(27 \%)$ had at least 1 GGO that developed a solid component. Fourteen patients $(20 \%)$ developed 1 or more new GGOs (mean, 1.8; 
TABLE 2. Characteristics of the dominant tumor and synchronous nondominant ground glass opacities

\begin{tabular}{|c|c|}
\hline Characteristic & Result (N = 70) \\
\hline \multicolumn{2}{|l|}{ Dominant tumor } \\
\hline Maximal diameter (mm) & $\begin{array}{r}20.0 \pm 11.0 \\
18[12-28]\end{array}$ \\
\hline Percent solid & $\begin{array}{l}52.6 \pm 27.0 \\
53[30-80]\end{array}$ \\
\hline \multicolumn{2}{|l|}{ Differentiation } \\
\hline Well & $34(48)$ \\
\hline Moderate & $34(48)$ \\
\hline Poor & $2(4)$ \\
\hline \multicolumn{2}{|l|}{ Pathologic stage } \\
\hline 0 & $5(7)$ \\
\hline IA & $44(63)$ \\
\hline IB & $18(26)$ \\
\hline IIA & $3(4)$ \\
\hline \multicolumn{2}{|l|}{ Mutations } \\
\hline EGFR & $24 / 43(56)$ \\
\hline L858R & $15 / 24(63)$ \\
\hline Exon 19 deletion & $6 / 24(25)$ \\
\hline Other & $3 / 24(12)$ \\
\hline ALK & $2 / 39(5)$ \\
\hline KRAS & $6 / 42(14)$ \\
\hline \multicolumn{2}{|l|}{ Nondominant GGOs } \\
\hline Initial number & $\begin{array}{c}1.8 \pm 1.3(\text { range }, 1-7) \\
1[1-2]\end{array}$ \\
\hline Size $(\mathrm{mm})$ & $\begin{array}{c}6.1 \pm 4.2(\text { range, } 2-23) \\
5[3-8]\end{array}$ \\
\hline Laterality per patient & $22(31)$ \\
\hline Unilateral & $48(69)$ \\
\hline \multicolumn{2}{|l|}{ Bilateral } \\
\hline \multicolumn{2}{|l|}{ Location per GGO } \\
\hline \multicolumn{2}{|l|}{ Ipsilateral lung } \\
\hline Same lobe & $12(10)$ \\
\hline Different lobe & $36(29)$ \\
\hline Contralateral lung & $76(21)$ \\
\hline
\end{tabular}

Values are presented as mean \pm standard deviation, median [interquartile range], $\mathrm{n}$ $(\%)$, or mutations found/total screened (\%). EGFR, Epidermal growth factor receptor; $G G O$, ground glass opacity.

range, 1-12). Thus, individual patients often displayed several changes with respect to GGOs that occurred simultaneously, each of which met our definition of GGO progression.

Eleven patients $(16 \%)$ experienced GGO progression that was determined to be substantial enough that a therapeutic intervention was performed (representing 52\% of patients who had any GGO progression). Six of these patients were treated with SBRT and 5 underwent surgical resection. The mean time to any GGO progression was 1.6 years (range, 0.26-7.0 years), and the mean time to intervention was 2.8 years (range, $0.7-9.3$ years). Of 6 patients treated with SBRT for GGO progression, 5 underwent biopsy before radiotherapy. The biopsy results demonstrated 4 adenocarcinomas and 1 lepidictype adenocarcinoma. Of 5 patients who underwent further surgical resection, pathology results indicated 2 adenocarcinomas with lepidic/bronchoalveolar carcinoma features; 1 papillary-predominant adenocarcinoma; 1 acinar-predominant adenocarcinoma; 1 pure in-situ lepidic-type adenocarcinoma; and 1 mucinous adenocarcinoma with lepidic, papillary, and micropapillary features. Two patients $(3 \%)$ developed extrapulmonary metastases, both to the brain. Overall patient survival over the mean 4.1-year follow-up was $92.9 \%$; diseasefree survival was $78.6 \%$. Two patients received erlotinib, but only after they developed distant (extrapulmonary) metastatic disease.

\section{Risk Factors for GGO Progression}

Table 4 shows 2 univariate analyses: 1 with outcome measure GGO progression and 1 with outcome measure GGO progression requiring treatment. Patients with GGO progression had significantly larger DTs that were more solid and were more often moderately poorly differentiated $(P=.0006, P=.003$, and $P=.04$, respectively) than patients with no GGO progression. A greater number of nondominant GGOs and larger, initial nondominant GGO size were also found to be associated with GGO progression. We did not have sufficient data on EGFR mutation status to carry out a statistically meaningful analysis on this factor.

Univariate analysis for factors associated with receiving treatment of a progressing GGO identified only larger initial size of the DT and larger initial size of the nondominant GGOs to be associated with subsequent intervention for a GGO.

A multivariate regression analysis was performed to identify independent risk factors for GGO progression (Table 5). A larger DT size (odds ratio, 1.07) and whether the largest nondominant GGO was $>1 \mathrm{~cm}$ at presentation (odds ratio, 4.98) were the 2 independent factors found significant for GGO progression. A multivariate analysis for the outcome of GGO progression requiring treatment was not performed because the number of events was too small for this analysis to be statistically valid. A logistic regression model (Table E1) with GGO progression as the outcome and size of largest other GGO as a continuous variable also showed that initial tumor size (odds ratio, $1.07 ; 95 \%$ confidence interval, 1.01-1.14) and size of largest other GGO (odds ratio, 1.15; 95\% confidence interval, 1.02-1.30) were significant.

\section{Survival}

Kaplan-Meier analyses (Figure 1, Figure E1, and Tables E2-E4) were performed comparing patients with GGO 
progression versus no progression, and no significant difference in survival was found $(P=.1)$. There was also no difference between survival curves of those with GGO progression that required treatment versus patients requiring no treatment of GGO progression $(P=.4)$. The model was also run with largest other GGO size as a continuous variable rather than dichotomized as $>$ or $<1 \mathrm{~cm}$ so the influence of specific size could be assessed, and that the odds ratio was $1.15 / \mathrm{mm}(95 \%$ confidence interval, 1.02-1.30; $P=.03$ ).

\section{DISCUSSION}

Thoracic surgeons, pulmonologists, and oncologists are increasingly confronted with lung adenocarcinoma patients with part-solid or predominately solid lesions presenting with several synchronous GGOs or part-solid nodules scattered throughout the lung parenchyma. It remains somewhat unclear what the appropriate staging and therapy should be for these patients. As our understanding of the unique characteristics of lepidic-type tumors has been developing, there is no doubt that many such patients have been deemed stage IIIA (T4 N0) or IV and triaged to systemic therapy alone-or perhaps received unnecessary postoperative adjuvant therapy.

In our institution, as our understanding of this disease process evolved, we moved progressively toward managing these patients in the following ways: proceed with a videoassisted thoracoscopic surgery procedure to resect the DT even when we believed we might not be able to find and resect a small, secondary GGO that could have been identifiable and resectable via thoracotomy and leave GGOs that were centrally placed in an ipsilateral, nonoperated lobe untouched. We believed that it would be better to leave a small GGO in place than to perform a pneumonectomy or bilobectomy for these types of lesions.

Although previous studies have begun to suggest that it is appropriate to offer local therapies (at least initially) to patients who have invasive, lepidic-type tumors that present with a limited number of synchronous GGOs, ${ }^{20-26}$ these studies have been insufficient to make this recommendation strongly. Further, the studies have not had sufficient power to allow a determination of risk factors for progression of untreated GGOs in this setting. It has remained, until now, quite possible that a subset of patients bearing these multifocal, lepidic-type tumors should not be treated with local therapy. It has remained possible that the longer-term prognosis is limited in this scenario, and/or that the GGOs that remain progress so frequently to needing additional intervention that the overall approach should be reconsidered. If any of these was found to be the case, then tyrosine kinase inhibitors, for the high proportion of these patients who bear EGFR mutations, might be the more appropriate initial therapy than surgical resection or SBRT.

We therefore designed this study with a larger sample size and longer follow-up time to allow more definitive recommendations to be made about the therapeutic approach to these patients and to allow risk factors for progression to be identified. An additional strength of our study is the fact that our subjects included a greater proportion of whites than

TABLE 3. Postoperative surveillance results

\begin{tabular}{|c|c|}
\hline Characteristic & Result $(\mathbf{N}=\mathbf{7 0})$ \\
\hline \multicolumn{2}{|l|}{ Overall patients with progression of unresected GGOs } \\
\hline Patients with unresected GGOs that grew & $19(27)$ \\
\hline Growth in diameter $(\mathrm{mm})$ & $5.0 \pm 5.2$ \\
\hline Growth in diameter $(\%)$ & $60.0 \pm 62.4$ \\
\hline Patients with unresected GGOs that gained a solid component & $19(27)$ \\
\hline Patients who developed new GGOs* & $13(19)$ \\
\hline Average number of new GGOs in these patients & $2.3 \pm 1.4$ \\
\hline \multicolumn{2}{|l|}{ Laterality of new GGOs to dominant tumor } \\
\hline Ipsilateral, number of new GGOs & $15(50)$ \\
\hline Contralateral & $15(50)$ \\
\hline \multicolumn{2}{|l|}{ Patients with intervention for GGO progression } \\
\hline Stereotactic radiotherapy & $6(9)$ \\
\hline Surgical resection & $5(7)$ \\
\hline Time to GGO progression (y) & $1.6 \pm 1.5$ \\
\hline Time to intervention for GGO progression (y) & $2.8 \pm 2.3$ \\
\hline Patients who developed extrapulmonary metastasis & $2(3)$ \\
\hline \multicolumn{2}{|l|}{ Survival } \\
\hline Overall & 92.9 \\
\hline Disease-free & 78.6 \\
\hline Without any GGO progression & 70.0 \\
\hline
\end{tabular}

Values are presented as mean \pm standard deviation, $\mathrm{n}(\%)$, or \%. GGO, Ground glass opacity. *See Table 4. 
TABLE 4. Patient characteristics stratified by ground glass opacity (GGO) progression and GGO progression requiring intervention

\begin{tabular}{|c|c|c|c|c|c|c|}
\hline Characteristic & $\begin{array}{c}\text { Any GGO } \\
\text { progression } \\
(\mathbf{n}=\mathbf{2 1}) \\
\end{array}$ & $\begin{array}{c}\text { No GGO } \\
\text { progression } \\
(\mathbf{n}=49) \\
\end{array}$ & $P$ value & $\begin{array}{c}\text { Treatment for } \\
\text { GGO progression } \\
(\mathbf{n}=11)\end{array}$ & $\begin{array}{l}\text { No treatment for } \\
\text { GGO progression } \\
\quad(\mathbf{n}=\mathbf{5 9}) \\
\end{array}$ & $P$ value \\
\hline \multirow[t]{2}{*}{ Age } & $73.6 \pm 7.6$ & $68.2 \pm 11.2$ & $.05^{*}$ & $74.5 \pm 8.4$ & $68.9 \pm 10.6$ & .1 \\
\hline & $72[67-78]$ & 69 [64-77] & .09 & $72[67-81]$ & $69[65-77]$ & .2 \\
\hline Female gender & $16(76)$ & $35(71)$ & .8 & $6(55)$ & $45(76)$ & .2 \\
\hline Asian race & $9(43)$ & $18(38)$ & .8 & $4(36)$ & $23(39)$ & 1 \\
\hline Smoker (any) & $12(57)$ & $29(59)$ & 1 & $6(55)$ & $35(59)$ & 1 \\
\hline \multicolumn{7}{|l|}{ Dominant tumor } \\
\hline Size (mm) & $\begin{array}{c}26.6 \pm 11.5 \\
26(18-34)\end{array}$ & $\begin{array}{l}17.2 \pm 9.5 \\
15(10-23)\end{array}$ & $\begin{array}{l}.0006^{*} \\
.002^{*}\end{array}$ & $\begin{array}{c}28.4 \pm 13.7 \\
30(12-41)\end{array}$ & $\begin{array}{l}18.4 \pm 9.7 \\
16(11-25)\end{array}$ & $\begin{array}{l}.005^{*} \\
.02^{*}\end{array}$ \\
\hline$\%$ solid & $\begin{array}{c}67 \pm 23 \\
80[55-85]\end{array}$ & $\begin{array}{c}47 \pm 26 \\
40[20-70]\end{array}$ & $\begin{array}{l}.003 * \\
.004 *\end{array}$ & $\begin{array}{c}65 \pm 26 \\
80[50-90]\end{array}$ & $\begin{array}{c}50 \pm 27 \\
50[20-75]\end{array}$ & $\begin{array}{l}.1 \\
.09\end{array}$ \\
\hline $\begin{array}{l}\text { Differentiation } \\
\text { Well } \\
\text { Moderate or poor }\end{array}$ & $\begin{array}{r}6(29) \\
15(71)\end{array}$ & $\begin{array}{l}28(57) \\
21(43)\end{array}$ & $.04 *$ & $\begin{array}{l}3(27) \\
8(73)\end{array}$ & $\begin{array}{l}31(52) \\
27(46)\end{array}$ & .08 \\
\hline $\begin{array}{l}\text { Number of nondominant GGOs } \\
\quad \leq 2 \\
>2\end{array}$ & $\begin{array}{r}14(67) \\
7(33)\end{array}$ & $\begin{array}{r}43(88) \\
6(12)\end{array}$ & $.05^{*}$ & $\begin{array}{l}7(64) \\
4(36)\end{array}$ & $\begin{array}{r}50(85) \\
9(15)\end{array}$ & .2 \\
\hline Largest nondominant GGO $>1 \mathrm{~cm}$ & $10(48)$ & $6(12)$ & $.004 *$ & $10(48)$ & $7(12)$ & $<.0001 *$ \\
\hline \multirow[t]{2}{*}{ Largest other GGO (mm) } & $9.6 \pm 7.0$ & $5.7 \pm 3.5$ & $.02^{*}$ & $13.8 \pm 7.3$ & $5.6 \pm 3.3$ & $.004 *$ \\
\hline & $7(4-14)$ & $5(3-6)$ & $.04 *$ & $14(8-20)$ & $5(4-6)$ & $.002 *$ \\
\hline \multirow[t]{2}{*}{ Mean GGO size (mm) } & $11.1 \pm 6.5$ & $5.2 \pm 3.0$ & $.03 *$ & $11.1 \pm 6.5$ & $5.2 \pm 2.8$ & $.01 *$ \\
\hline & $7(4-10)$ & $5(3-6)$ & $.03 *$ & $10(8-15)$ & $5(3-6)$ & $.003 *$ \\
\hline
\end{tabular}

prior literature, which has focused entirely on Asian populations, thus broadening the generalizability of these findings, at least to white populations.

Our key findings are as follows. First, even at a mean follow-up of 4.1 years, only $15.7 \%$ of patients with unresected GGOs in the setting of a resected pNO DT underwent subsequent surgical or radiotherapeutic intervention for a progressing GGO. This is an approximate doubling of the percentage of patients who underwent intervention for a progressing GGO in our previous study, which had a shorter

TABLE 5. Multivariate regression analysis using risk factors found significant for ground glass opacity (GGO) progression on univariate analysis

\begin{tabular}{|c|c|c|c|}
\hline Variable & $\begin{array}{c}\text { Odds ratio for } \\
\text { GGO progression }\end{array}$ & $\begin{array}{l}\text { 95\% Confidence } \\
\text { interval }\end{array}$ & $P$ value \\
\hline Age & 1.04 & $0.97-1.12$ & .3 \\
\hline $\begin{array}{l}\text { Dominant tumor } \\
\text { size }(\mathrm{mm})\end{array}$ & 1.07 & $1.01-1.14$ & $.04 *$ \\
\hline$\%$ solid & 1.02 & $0.99-1.05$ & .08 \\
\hline $\begin{array}{l}\text { More than } 2 \text { other } \\
\text { GGOs }\end{array}$ & 2.78 & $0.62-12.50$ & .2 \\
\hline $\begin{array}{l}\text { Largest other GGO } \\
\quad>1 \mathrm{~cm}\end{array}$ & 4.98 & $1.15-21.28$ & $.03 *$ \\
\hline
\end{tabular}

mean follow-up of 2.6 years. It is important to point out that an additional $15 \%$ of patients at a mean follow-up of 4.1 years experienced GGO progression that, although not yet believed to require treatment, may ultimately require treatment.

Second, although we identified several features reflective of greater initial tumor burden that are associated with GGO growth or need for subsequent intervention (2 of which were significant on multivariate analysis), neither GGO growth nor requirement for an intervention negatively affected survival. This suggests that even those patients with a multifocal presentation of lepidic-type adenocarcinoma in our cohort who are at highest risk for progression should not be denied local therapy for a pNO DT. These findings suggest that closer surveillance may be indicated in patients who have a larger DT or a GGO that is larger than $1 \mathrm{~cm}$, both of which are independently associated with GGO progression.

The fact that those patients who experienced GGO progression actually had better (although not significantly better) survival than those who did not experience GGO progression may simply be a function of the small sample size in this analysis. However, it may also suggest that perhaps some patients in the no-progression group did not in fact have in situ adenocarcinoma or atypical adenomatous hyperplasia within their CT-identified GGOs. Rather, 

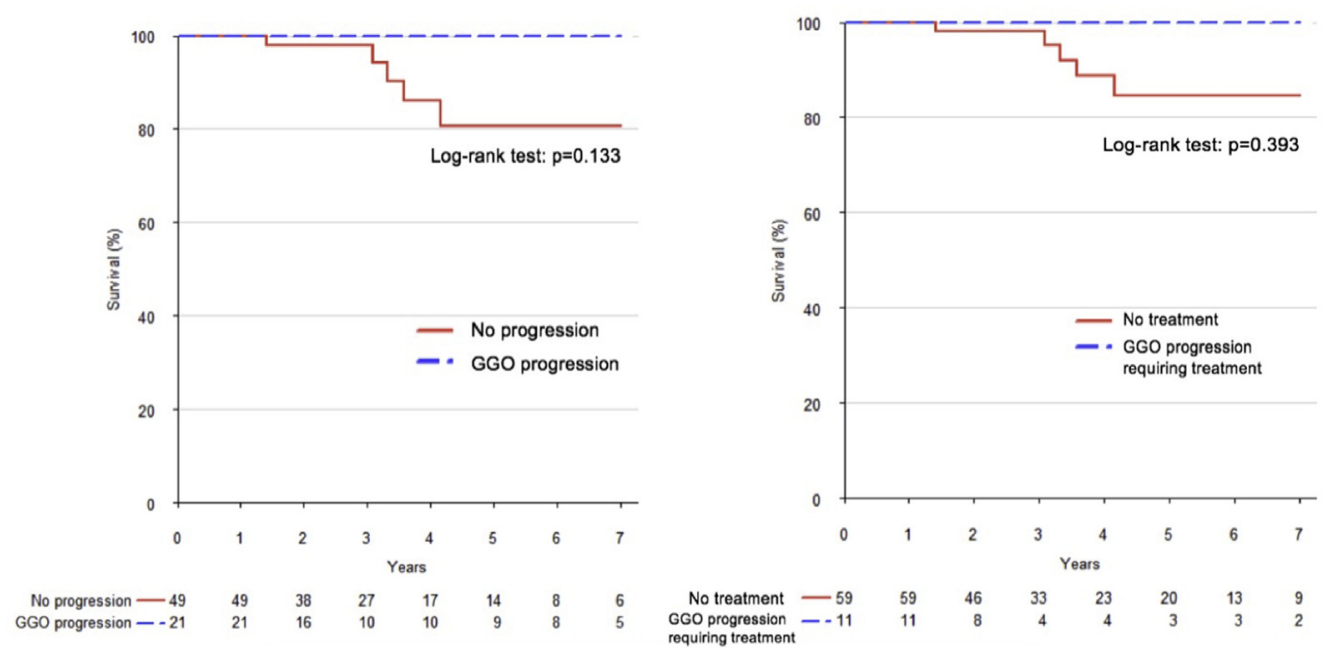

FIGURE 1. Kaplan-Meier analysis shows that survival in patients with either ground glass opacity $(G G O)$ progression or GGO progression requiring treatment was not significantly different $(P=.133$ and $P=.393)$ from patients without GGO progression. Kaplan-Meier analysis of patients with GGO progression who were not treated is available in Figure E1. Confidence intervals are available in Tables E1-E3.

these patients' GGOs could represent entirely benign lesions. Although this is purely speculative, if it is true, then the dominant tumors in some of these no-progression patients might be better categorized as the more classic, solid type of adenocarcinoma that typically present as solitary lesions - tumors that tend to have a worse prognosis than tumors bearing a lepidic component that often present multifocally. This suggests that having a limited number of synchronous foci of atypical adenomatous hyperplasia or in situ adenocarcinoma is actually a positive prognostic sign. Overall, the most balanced assessment of these survival results are likely that the strategy of resection and follow-up tempered with repeat intervention for progression of GGOs leads to very good clinical outcomes.

In our practice, we typically consider treating a nondominant GGO that is being followed, by either surgery or SBRT, when it reaches $>1 \mathrm{~cm}$ in size with any solid component, or $>1.5 \mathrm{~cm}$ in size if entirely ground glass on thinsection CT. This study provides evidence that it is safe to monitor unresected GGOs until they reach approximately that point. It may be safe to follow them beyond these cutoffs, particularly if they remain entirely ground glass on thin-section CT. This remains to be clearly established.

Although our study contained 70 patients followed for a mean of 4.1 years - the largest cohort versus any previous study of this tumor presentation-we were still somewhat limited by this sample size and the resulting limited statistical power. We were unable to analyze the effect of some potential risk factors, such as mutation status, on survival due to the small size of each population subset and the limited number of deaths in the entire cohort follow-up. The survival difference seen between the cohorts may stem from this small number of events. We were also limited by all of the inherent biases of retrospective studies. The fact that none of our subjects had more than 7 synchronous GGOs, and that patients with dominant tumors $>5 \mathrm{~cm}$ in maximal diameter or with pathologic stage $>1$ were excluded, prevents us from drawing conclusions about these subgroups.

\section{CONCLUSIONS}

This study establishes that a substantial percentage $(15.7 \%)$ of patients who undergo surgical resection of a node-negative invasive adenocarcinoma while harboring up to 7 synchronous GGOs will undergo treatment for 1 of those GGOs at a mean follow-up of 4.1 years. Most importantly, growth of GGOs and even need for an intervention for a progressing GGO does not negatively influence survival. Overall survival in these patients with multifocal lepidic-type tumors remains extremely high. Therefore, even those patients with tumor characteristics that are associated with subsequent treatment of a GGO-such as a larger dominant tumor or an initial synchronous GGO $>1$ $\mathrm{cm}$ - should not be denied potentially curative local therapy for their dominant tumor.

\section{Conflict of Interest Statement}

Authors have nothing to disclose with regard to commercial support.

\section{References}

1. Travis WD, Brambilla E, Noguchi M, Nicholson AG, Geisinger KR, Yatabe Y, et al. International Association for the Study of Lung Cancer/American Thoracic Society/European Respiratory Society international multidisciplinary classification of lung adenocarcinoma. J Thorac Oncol. 2011;6:244-85. 
2. Liu Y, Kim J, Qu F, Liu S, Wang H, Balagurunathan Y, et al. CT features associated with epidermal growth factor receptor mutation status in patients with lung adenocarcinoma. Radiology. 2016;280:271-80.

3. Hasegawa M, Sakai F, Ishikawa R, Kimura F, Ishida H, Kobayashi K, et al. CT Features of epidermal growth factor receptor-mutated adenocarcinoma of the lung: comparison with nonmutated adenocarcinoma. J Thorac Oncol. 2016;11: 819-26.

4. Hong SJ, Kim TJ, Choi YW, Park JS, Chung JH, Lee KW. Radiogenomic correlation in lung adenocarcinoma with epidermal growth factor receptor mutations: imaging features and histological subtypes. Eur Radiol. 2016;26:3660-8.

5. Ozkan E, West A, Dedelow JA, Chu BF, Zhao W, Yildiz VO, et al. CT Gray-Level texture analysis as a quantitative imaging biomarker of epidermal growth factor receptor mutation status in adenocarcinoma of the lung. AJR Am J Roentgenol. 2015;205:1016-25.

6. Yang Y, Yang Y, Zhou X, Song X, Liu M, He W, et al. EGFR L858R mutation is associated with lung adenocarcinoma patients with dominant ground-glass opacity. Lung Cancer. 2015;87:272-7.

7. Lee HJ, Kim YT, Kang CH, Zhao B, Tan Y, Schwartz LH, et al. Epidermal growth factor receptor mutation in lung adenocarcinomas: relationship with CT characteristics and histologic subtypes. Radiology. 2013;268:254-64.

8. Herbst RS, Prager D, Hermann R, Fehrenbacher L, Johnson BE, Sandler A, et al. TRIBUTE: a phase III trial of erlotinib hydrochloride (OSI-774) combined with carboplatin and paclitaxel chemotherapy in advanced non-smallcell lung cancer. J Clin Oncol. 2005;23:5892-9.

9. Clark GM, Zborowski DM, Santabarbar P, Ding K, Whitehead M, Seymour L, et al. Smoking history and epidermal growth factor receptor expression as predictors of survival benefit from erlotinib for patients with non-small-cell lung cancer in the National Cancer Institute of Canada Clinical Trials Group study BR.21. Clin Lung Cancer. 2006; 7:389-94.

10. Yoshizawa A, Sumiyoshi S, Sonobe M, Kobayashi M, Fujimoto M, Kawakami F, et al. Validation of the IASLC/ATS/ERS lung adenocarcinoma classification for prognosis and association with EGFR and KRAS gene mutations: analysis of 440 Japanese patients. J Thorac Oncol. 2013;8:52-61.

11. Okada M. Subtyping lung adenocarcinoma according to the novel $201 \mathrm{IASLC/}$ ATS/ERS classification: correlation with patient prognosis. Thorac Surg Clin. 2013;23:179-86.

12. Burt BM, Leung AN, Yanagawa M, Chen W, Groth SS, Hoang CD, et al. Diameter of solid tumor component alone should be used to establish T stage in lung adenocarcinoma. Ann Surg Oncol. 2015;22(Suppl 3):S1318-23.

13. Noguchi M, Morikawa A, Kawasaki M, Matsuno Y, Yamada T, Hirohashi S, et al. Small adenocarcinoma of the lung. Histologic characteristics and prognosis. Cancer. 1995; 75:2844-52.

14. Asamura H, Suzuki K, Watanabe S, Matsuno Y, Maeshima A, Tsuchiya R, et al. A clinicopathological study of resected subcentimeter lung cancers: a favorable prognosis for ground glass opacity lesions. Ann Thorac Surg. 2003;76:1016-22.

15. Okada M, Nishio W, Sakamoto T, Uchino K, Hanioka K, Ohbayashi C, et al. Correlation between computed tomographic findings, bronchioloalveolar carcinoma component, and biologic behavior of small-sized lung adenocarcinomas. $J$ Thorac Cardiovasc Surg. 2004;127:857-61.

16. Daly RC, Trastek VF, Pairolero PC, Murtaugh PA, Huang MS, Allen MS, et al. Bronchoalveolar carcinoma: factors affecting survival. Ann Thorac Surg. 1991; $51: 368-76$
17. Yamato Y, Tsuchida M, Watanabe T, Aoki T, Koizumi N, Umezu H, et al. Early results of a prospective study of limited resection for bronchioloalveolar adenocarcinoma of the lung. Ann Thorac Surg. 2001;71:971-4.

18. Koike T, Togashi K, Shirato T, Sato S, Hirahara H, Sugawara M, et al. Limited resection for noninvasive bronchioloalveolar carcinoma diagnosed by intraoperative pathologic examination. Ann Thorac Surg. 2009;88:1106-11.

19. Watanabe S, Watanabe T, Arai K, Kasai T, Haratake J, Urayama H, et al Results of wedge resection for focal bronchioloalveolar carcinoma showing pure ground-glass attenuation on computed tomography. Ann Thorac Surg. 2002;73:1071-5.

20. Roberts PF, Straznicka M, Lara PN, Lau DH, Follette DM, Gandara DR, et al Resection of multifocal non-small cell lung cancer when the bronchioloalveolar subtype is involved. J Thorac Cardiovasc Surg. 2003;126:1597-602.

21. Martini N, Melamed MR. Multiple primary lung cancers. J Thorac Cardiovasc Surg. 1975;70:606-12.

22. Gu B, Burt BM, Merritt RE, Stephanie S, Nair V, Hoang CD, et al. A dominant adenocarcinoma with multifocal ground glass lesions does not behave as advanced disease. Ann Thorac Surg. 2013;96:411-8.

23. Tsutsui S, Ashizawa K, Minami K, Tagawa T, Nagayasu T, Hayashi T, et al. Multiple focal pure ground-glass opacities on high-resolution CT images: clinical significance in patients with lung cancer. AJR Am J Roentgenol. 2010; 195:131-8.

24. Nakata M, Sawada S, Yamashita M, Saeki H, Kurita A, Takashima S, et al. Surgical treatments for multiple primary adenocarcinoma of the lung. Ann Thorac Surg. 2004;78:1194-9.

25. Mun M, Kohno T. Efficacy of thoracoscopic resection for multifocal bronchioloalveolar carcinoma showing pure ground-glass opacities of $20 \mathrm{~mm}$ or less in diameter. J Thorac Cardiovasc Surg. 2007;134:877-82.

26. Kim HK, Choi YS, Kim J, Shim YM, Lee KS, Kim K. Management of multiple pure ground-glass opacity lesions in patients with bronchioloalveolar carcinoma. J Thorac Oncol. 2010;5:206-10.

27. Hattori A, Matsunaga T, Takamochi K, Oh S, Suzuki K. Surgical management of multifocal ground-glass opacities of the lung: correlation of clinicopathologic and radiologic findings. J Thorac Cardiovasc Surg. 2017;65:142-9.

28. Shimada Y, Saji H, Otani K, Maehara S, Maeda J, Yoshida K, et al. Survival of a surgical series of lung cancer patients with synchronous multiple ground-glass opacities, and the management of their residual lesions. Lung Cancer. 2015; 88:174-80.

29. Port JL, Korst RJ, Lee PC, Kansler AL, Kerem Y, Altorki NK. Surgica resection for multifocal (T4) non-small cell lung cancer: is the T4 designation valid? Ann Thorac Surg. 2007;83:397-400.

30. Vansteenkiste JF, De Belie B, Deneffe GJ, Demedts MG, De Leyn PR Van Raemdonck DE, et al. Practical approach to patients presenting with multiple synchronous suspect lung lesions: a reflection on the current TNM classification based on 54 cases with complete follow-up. Lung Cancer. 2001 34:169-75.

Key Words: adenocarcinoma, lepidic, multifocal, adenocarcinoma in situ, non-small cell lung cancer, multiple pulmonary nodules 


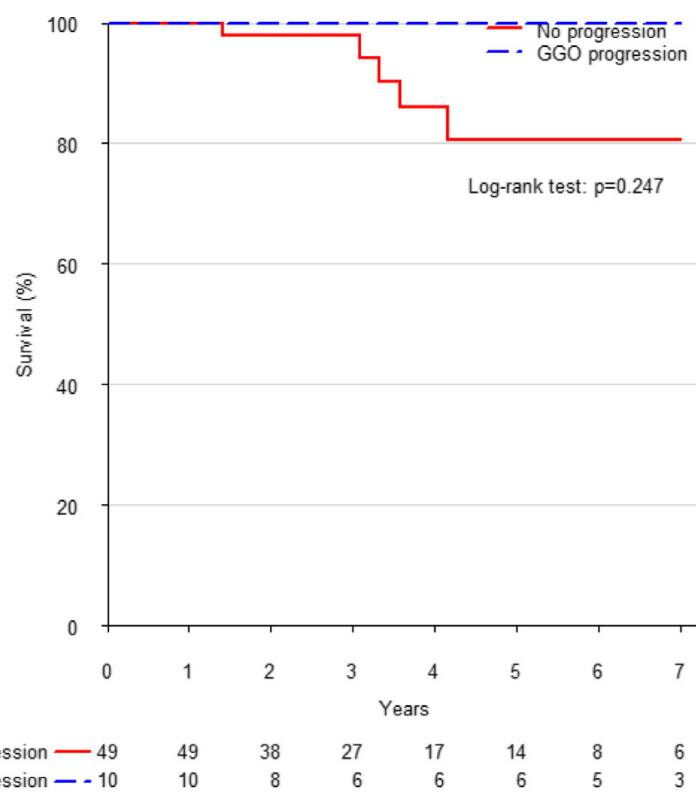

FIGURE E1. Comparison of 49 patients with no progression and 10 patients with ground glass opacity $(G G O)$ progression that was not treated.
TABLE E2. Survival (95\% confidence interval) stratified by years 1 through 5 for any ground glass opacity (GGO) progression

\begin{tabular}{lcc}
\hline Year & No progression & Any GGO progression \\
\hline 1 & $100 \%(100-100)$ & $100 \%(100-100)$ \\
2 & $97.9 \%(93.8-100)$ & $100 \%(100-100)$ \\
3 & $97.9 \%(93.8-100)$ & $100 \%(100-100)$ \\
4 & $86.1 \%(74.0-100)$ & $100 \%(100-100)$ \\
5 & $80.7 \%(66.2-98.3)$ & $100 \%(100-100)$ \\
\hline$G G O$, Ground glass opacity.
\end{tabular}

$G G O$, Ground glass opacity.

TABLE E1. Logistic regression model with any ground glass opacity (GGO) progression as the outcome, and using size of largest other GGO as a continuous variable instead of as categorized as $>$ or $<1 \mathrm{~cm}$

\begin{tabular}{lccc}
\hline \multicolumn{1}{c}{ Variable } & Odds ratio & 95\% Confidence interval & $P$ value \\
\hline Age & 1.06 & $0.98-1.14$ & .1 \\
Initial tumor size $(\mathrm{mm})$ & 1.07 & $1.01-1.14$ & $.03^{*}$ \\
\% solid & 1.02 & $0.99-1.05$ & .1 \\
More than 2 other GGOs & 3.24 & $0.74-14.08$ & .1 \\
Size of largest other GGO $(\mathrm{mm})$ & 1.15 & $1.02-1.30$ & $.03^{*}$ \\
\hline
\end{tabular}

$\overline{G G O}$, Ground glass opacity. *Statistically significant at a significance level of $P<.05$. 
TABLE E3. Survival ( $95 \%$ confidence interval) stratified by years 1 through 5 for any ground glass opacity (GGO) progression that required treatment

\begin{tabular}{lcc}
\hline Year & No progression & $\begin{array}{c}\text { Any GGO progression } \\
\text { requiring treatment }\end{array}$ \\
\hline 1 & $100 \%(100-100)$ & $100 \%(100-100)$ \\
2 & $98.2 \%(94.9-100)$ & $100 \%(100-100)$ \\
3 & $98.2 \%(94.9-100)$ & $100 \%(100-100)$ \\
4 & $88.7 \%(78.6-100)$ & $100 \%(100-100)$ \\
5 & $84.7 \%(72.8-98.5)$ & $100 \%(100-100)$ \\
\hline
\end{tabular}

GGO, Ground glass opacity.
TABLE E4. Comparison of 49 patients with no progression and 10 patients with ground glass opacity (GGO) progression that was not treated

\begin{tabular}{lcc}
\hline Year & No progression & Any GGO progression \\
\hline 1 & $100 \%(100-100)$ & $100 \%(100-100)$ \\
2 & $97.9 \%(93.8-100)$ & $100 \%(100-100)$ \\
3 & $97.9 \%(93.8-100)$ & $100 \%(100-100)$ \\
4 & $86.1 \%(74.0-100)$ & $100 \%(100-100)$ \\
5 & $80.7 \%(66.2-98.3)$ & $100 \%(100-100)$ \\
\hline$G G O$, Ground glass opacity.
\end{tabular}

